Full length article

\title{
State-level medical marijuana laws, marijuana use and perceived availability of marijuana among the general U.S. population
}

\author{
Silvia S. Martins ${ }^{a}, *$, Christine M. Mauro ${ }^{a}$, Julian Santaella-Tenorio ${ }^{a}$, June H. Kim ${ }^{a}$, \\ Magdalena Cerda $^{b}$, Katherine M. Keyes a , Deborah S. Hasin ${ }^{a}$, Sandro Galea ${ }^{c}$, \\ Melanie Wall ${ }^{\mathrm{a}}$ \\ a Columbia University, New York, United States \\ b University of California, Davis, United States

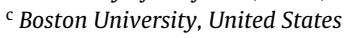

\section{A R T I C L E I N F O}

\section{Article history:}

Received 10 May 2016

Received in revised form 4 October 2016

Accepted 5 October 2016

Available online 11 October 2016

\section{Keywords:}

Medical marijuana laws

Cannabis

Availability

Marijuana use

\begin{abstract}
A B S T R A C T
Background: Little is known on how perceived availability of marijuana is associated with medical marijuana laws. We examined the relationship between medical marijuana laws (MML) and the prevalence of past-month marijuana use, with perceived availability of marijuana.

Methods: Data were from respondents included in the National Survey of Drug Use and Health restricted use data portal 2004-2013. Multilevel logistic regression of individual-level data was used to test differences between MML and non-MML states and changes in prevalence of past-month marijuana use and perceived availability from before to after passage of MML among adolescents, young adults and older adults controlling for demographics.

Results: Among adults 26+, past-month prevalence of marijuana use increased from $5.87 \%$ to $7.15 \%$ after MML passage (Adjusted Odds Ratio(AOR): 1.24 [1.16-1.31]), but no change in prevalence of use was found for 12-17 or 18-25 year-olds. Perceived availability of marijuana increased after MML was enacted among those $26+$ but not in younger groups. Among all age groups, prevalence of marijuana use and perception of it being easily available was higher in states that would eventually pass MML by 2013 compared to those that had not. Perceived availability was significantly associated with increased risk of past-month marijuana use in all age groups.

Conclusion: Evidence suggests perceived availability as a driver of change in use of marijuana due to MML. To date, this has only occurred in adults $26+$ and different scenarios that could explain this change need to be further explored.
\end{abstract}

(c) 2016 Elsevier Ireland Ltd. All rights reserved.

\section{Introduction}

A major concern with the enactment of medical marijuana laws (MML) is that this type of legislation could potentially increase marijuana use in adolescents and adult populations (Cerdá et al., 2012). A potential pathway in which this may occur involves the recognition that MML have been passed and could be increasing the availability of marijuana in the U.S. Increases in availability of marijuana on its own may normalize both medical and nonmedical marijuana use and reduce harm-related risk perceptions of marijuana use, which could result in changes in marijuana use (Bestrashniy and Winters, 2015; Palamar et al., 2014; Piontek et al.,

* Corresponding author at: Columbia University, Epidemiology, 722 West 168th Street Columbia University, New York, NY 10032, United States.

E-mail address: ssm2183@columbia.edu (S.S. Martins).
2013). Some studies suggest that individuals' perception of availability of an illegal drug can also influence drug use patterns (Ennett et al., 1997; Hanson et al., 2003). Increased availability of marijuana may generate changes in the supply market resulting in drops in price of marijuana, which in turn may influence the overall use of it in the population (Pacula et al., 2015). However, although it is believed to have increased over the last decade, estimates of yearly availability of marijuana in the U.S. either produced domestically or internationally are unknown (NDIC, 2010).

Recent evidence suggests that, while not all MML states have enforced patient registration, the number of patients registered in medical marijuana programs across states have increased over time in MML states, particularly after 2009 when there were substantial changes in federal prosecution laws regarding marijuana cultivation, distribution and possession (Fairman, 2016). In addition, registration fees vary widely across MML states (Williams, 2016) Also, research has reported that home cultivation and the 
presence of dispensaries in MML states have resulted in diversion of marijuana to individuals (Nussbaum et al., 2015; RMHIDTA, 2014; Wirfs-Brock et al., 2010), including youth (Salomonsen-Sautel et al., 2012; Thurstone et al., 2011), who then use it for non-medical purposes. Non-MML states may also be affected by the diversion of marijuana illegally moving from MML states to non-MML states (RMHIDTA, 2014). All these factors could have potentially increased the overall availability of marijuana across states; however, it is also possible that other factors, such as reductions in illegal marijuana coming from out of the U.S. (UNODC, 2015; i.e., there has been a decrease in seizures of illegal marijuana entering in the U.S. since 2009), could have balanced out the MML effects. As such, measuring the availability of marijuana across states in a specific year is challenging given the limitations to quantify the amount of available of marijuana in illegal street-markets and sold through the Internet, and the surplus of medical marijuana from home cultivation productions and legal dispensaries that is diverted to the public (Pacula et al., 2015; Smart, 2015). Smart (2015) has reported that growth in the legal medical marijuana market is associated with increases in recreational use among adolescent and adults. In this regard, measures of overall perception of availability could be an intermediate step between changes in actual availability and marijuana use, and could provide some insight on how availability is associated with marijuana use in states enacting MML.

To date, some studies have examined if perceived availability is associated with the prevalence of marijuana use (Bonn-Miller et al., 2014; Friese and Grube, 2013; Khatapoush and Hallfors, 2004; Miech et al., 2015; Salomonsen-Sautel et al., 2012; Schuermeyer et al., 2014; Smart, 2015). However, these studies are restricted populations of only medical users (Bonn-Miller et al., 2014), had limited to analyses in a single state (Bonn-Miller et al., 2014; Friese and Grube, 2013; Khatapoush and Hallfors, 2004), only explored perceived availability as an outcome of marijuana policies in the mid to late 1990s (Khatapoush and Hallfors, 2004), or mostly have focused on youth populations (Friese and Grube, 2013; Kokkevi et al., 2000; Miech et al., 2015; Piontek et al., 2013; Steppan et al., 2013; ter Bogt et al., 2006, 2014). Data from the Monitoring the Future (MTF) study has shown that perceived availability among 12th graders has been stable since 1975 (80-90\% report it is fairly easy to obtain marijuana), has always been higher in 12 th graders as compared to 8 th and 10th graders (37\% of the 8th graders and $66 \%$ of the 10 th graders reported it was fairly easy to obtain in 2014) and is currently at a historic low among this population (Miech et al., 2015). In addition, another study with MTF data (Shi, 2016) shows that 8th grade students from schools located close to medical marijuana dispensaries (short traveling distance, $<5$ miles) were more likely to have recently use marijuana compared to those from schools located farther apart from dispensaries ( $>25$ miles). To date, there is little information on how perceived availability is associated with marijuana use among adults, those comprising the majority of licensed medical marijuana users (Anderson et al., 2015a), as well as the total overall users of marijuana. To our knowledge, no study has investigated whether perceived availability of marijuana is associated with the relationship between state medical marijuana laws and the state-level differences in prevalence of marijuana use in the U.S. general population. Also, although evidence suggests that MML are associated with increases in marijuana use among those ages 21 and older (Wen et al., 2015), is not clear if all adults (age sub-groups) have been influenced in the same way and whether perceived availability could be linked to increase use across all age sub-groups. Our study aims to address these gaps.

In addition, because MML are intended to target mostly the population of older patients with illnesses that can be potentially be treated with medical marijuana (e.g., chronic pain or cancer; Fairman, 2016), it is likely that MML laws affect different age groups differently, and through different modes of access (Hasin et al., 2015). Understanding the potential externalities of MML in different age groups, such as potential increases in recreational marijuana use among adolescents, young adults and older adults, would improve our understanding of the effects of marijuana policies and provide information about the types of public health responses that should accompany major policy changes related to marijuana.

Therefore, the aims of this paper are: 1 ) To examine the relationship between state-level MML and past-month marijuana use among adolescents, young adults and older adults in the US household population from 2004 to 2013; 2) To examine whether state-level MML is associated with perceptions of marijuana availability; and 3) To assess whether perceptions of marijuana availability are associated with past-month marijuana use among adolescents, young adults and older adults.

\section{Methods}

\subsection{Data}

Observationscame from ten years of annual cross-sectional survey data from the National Survey of Drug Use and Health (NSDUH) restricted use data portal 2004-2013 (CBHSQ 2015). Since 2004 (first year in which restricted-access NSDUH data are made available), data on more than 17,500 youth (12-17 years-old), 17,500 young adults (18-25 years-old) and 18,800 adults older than 26 years old have been collected yearly in the NSDUH. The NSDUH was designed to produce estimates of drug and alcohol use prevalence, as well as drug use patterns and their consequences, in the general U.S. civilian population aged 12 and older. Multi-stage probability sampling designs are used to collect the annual cross sectional surveys. The survey employs a 50 state design with an independent multistage area probability sample for each state and the District of Columbia. Importantly, the survey design allows for computation of estimates that are representative of each state in all 50 States plus the District of Columbia. Younger age groups (youths aged 12-17 and young adults aged 18-25) are oversampled. Each state's sample was therefore approximately equally distributed among three major age groups: $12-17$ years, $18-25$ years, and 26 years or older. Design-based weights adjust for nonresponse and post-stratify to the known total US population aged 12 and older. Professional field interviewers collect information using computerassisted interviewing methods, including audio computer-assisted self-interviewing that had built-in skip, logic, and consistency checks. This use of audio computer-assisted self-interviewing provides respondents with a highly private and confidential means of responding to sensitive questions, increasing the level of honest reporting of illegal drug use and other sensitive behaviors (SAMHSA, 2006, 2007, 2012). Survey screening response rates vary from $84 \%$ to $91 \%$ and interview response rates vary from $72 \%$ to $77 \%$ during these years. The reliability and validity of the NSDUH measures has been documented (Harrison et al., 2007; Hunter et al., 2005; Piper et al., 2006; SAMHSA, 2010).

\subsection{Measures}

2.2.1. Primary exposure variables: state-level medical marijuana laws. Our primary exposure was state-level MML, parameterized as a time-varying 3-level variable indicating whether the state had a MML in a particular year or not, as determined through review of state policies by legal scholars, economists, and policy analysts at RAND Corporation (Pacula et al., 2014) (Supplementary Table S1). States without MML by 2013 were coded as "never" states for all years in our data (2004-2013). States enacting MML were coded as "before" for the years in which they had not yet enacted a MML, and 
as "after" for the year in which they enacted a MML and also all years after. The 11 states that passed MML prior to or during 2004 were coded as "after" on this variable for all years from 2004 to 2013. This strategy enabled us to examine before versus after change in risk of marijuana use and availability within the 10 states that passed MML during 2005-2013, while controlling for contemporaneous trends in states that never enacted MML.

\subsubsection{Outcomes.}

2.2.2.1. Individual-level past-month marijuana use. NSDUH participants answered whether they had used marijuana during the past month. This variable was dichotomous indicating any use or not in the past month.

2.2.2.2. Individual-level perceived availability of marijuana. In the NSDUH, all respondents answered one question regarding current perceived availability of marijuana. Respondents were asked "The next questions ask how difficult you think it would be for you to get each of the following types of drugs, if you wanted some. How difficult or easy would it be for you to get some marijuana, if you wanted some?", with these possible answers being offered: probably impossible, very difficult, fairly difficult, fairly easy or very easy. We dichotomized this variable into those reporting that marijuana was fairly or very easy to obtain vs. all others, similar to the approach used in Schuermeyer et al., 2014.

2.2.3. Individual-level covariates. Individual-level control variables included sex, race/ethnicity (Non-Hispanic White, Non-Hispanic Black, Hispanic, Non-Hispanic Mixed Race, Asian/Native American/Native Hawaiian/Pacific Islander), insurance status (yes/no) and annual household family income (4 levels). Also included was a contextual covariate indicating population density of the location of the household (Core-Based Statistical Area (CBSA): CBSA with more than 1 million persons, CBSA with less than 1 million persons, not in a CBSA).

2.2.4. State-level covariates. State-level control variables included proportion of each state's population male, white, aged 10-24, and at least high school education in population aged $>25$ years, state unemployment rate and median household income. Census values from 2000 and 2010 were used for 2004-2005 and 2006-2013, respectively.

\subsection{Statistical analyses}

For descriptive purpose, the prevalence of marijuana use in the past-month and the prevalence of endorsing that marijuana was "fairly" or "very easy" to obtain were calculated for each year, 2004-2013, by averaging NSDUH weighted state level prevalence estimates across three MML groups (according to whether MML states had pre/post-MML NSDUH data): 1) states without MML by 2013; 2) states having pre/post-MML data during the study period, i.e., those enacting laws from 2005 to 2013 (RI, NM, MI, AZ, NJ, DE, CT, MA, IL, NH, because states enacting laws in 2004 do not have pre-MML data they are not included in this group); 3) states with only post-MML data, i.e., states enacting MML before or during 2004 (CA, OR, WA, AK, ME, CO, NV, HI, MD, MT, VT) (Fig. 1A and B). Summaries were stratified by three age groups: $12-17,18-26$, and 26 and older consistent with NSDUH sampling design. The District of Columbia was not included in the analyses.

Multilevel logistic regression was used to test the association between MML and individual-level past-month marijuana use and perceived availability. Separate models were fit for each outcome with a primary state-level predictor indicating MML status by year: never passed (non-MML), before MML passage, or after MML passage and controlling for historical trends in marijuana use across the 2004-2013 years using a piecewise cubic spline function (de Boor, 1978) of year with a knot at 2008, other individual- and statelevel covariates described above, and a random intercept for state to account for clustering of individuals within states (see Supplementary material 1 for the model and SAS Proc GLIMMIX code). The estimated variance of the random state intercept was statistically significant in all models indicating its need to be included to control for clustering of responses at the state level. Models were stratified by age in three categories (12-17, 18-25, 26+). In post-hoc analyses, the $26+$ age group was subdivided into three additional age groups (26-39, 40-64, 65+) to examine whether associations between MML and marijuana use and perceived availability differed across the adult sub-group.

From the fitted multilevel logistic regression, adjusted prevalence of use was estimated by age group for states that never passed a MML, states before they passed a MML and states after they passed a MML using least squares means. Further, adjusted odds ratios (AORs) and 95\% confidence intervals (CI) for the "Before vs. Never" and "After vs. Before" contrasts were also computed for each of the three age groups. Sampling weights were not included, as the model directly incorporated all individual- level variables related to the sampling design (Little, 2004).

To assess whether perceived availability of marijuana is associated with past-month marijuana use, an additional model was fit. The model was the same as the model described above with past month marijuana use as the outcome, but with the addition of individual level perceived availability as a predictor.

As a sensitivity analysis, all three of the models discussed above were also fit using logistic regression treating state as a fixed effect, rather than as random effect, yielding similar results (not shown, available upon request). All analyses were carried out in SAS (SAS version 9.3, Cary, NC, USA) available in the SAMHSA data portal.

\section{Results}

Past-month prevalence of marijuana use and perceived availability (marijuana is fairly or very easy to obtain) during the 2004-2013 period was higher among individuals aged 18-25 compared with those ages $12-17$ and those 26 or older regardless of MML state status (Fig. 1A,B).

States that ever passed MML had higher prevalence of pastmonth marijuana use in each age group before passing MML compared to states that never passed these laws (Table $1 \mathrm{~A}$ and Fig. 1A). However, among 12-17 and 18-25 year-olds, there was no evidence that MML were related to changes in the prevalence of past-month marijuana use during the study period (Table 1B) (After vs. Before MML: $12-17$ yrs old $A O R=1.03,95 \%$ confidence interval $[\mathrm{CI}]: 0.97,1.09 ; 18-25$ yrs old $\mathrm{AOR}=0.97, \mathrm{CI}: 0.93,1.02$ ). Among individuals ages 26 and older, there was an increase in prevalence of past-month marijuana use after MML (7.15\%) compared to before $(5.87 \%)$ (AOR: $1.24,95 \% \mathrm{CI}: 1.16,1.31)$ during the study period (2004-2013). Further, when the age 26+ was subdivided into three subgroups (26-39, 40-64, 65+), prevalence of past-month marijuana use increased after MML passage in all of the older age groups. In those 26-39, prevalence increased from $8.9 \%$ to $10.2 \%(A O R=1.2[1.1,1.3], \mathrm{p}<0.0001)$; among those $40-64$, from $4.5 \%$ to $6.0 \%$ (AOR: $1.4[1.2,1.5], \mathrm{p}<0.0001$ ); and among those $65+$ from $0.3 \%$ to $0.8 \%$ (AOR: $2.6[1.5,4.6], \mathrm{p}=0.0006$ ) (Supplementary Table S2).

Similar to the findings between MML enactment and marijuana use, states that eventually passed MML had higher perception of easy availability of marijuana even before passage (Table $2 \mathrm{~A}$ and Fig. 1B). Also similar to marijuana use, there was no effect of MML 
A)

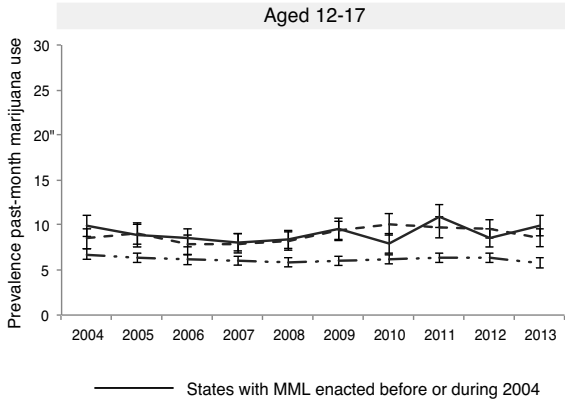

B)

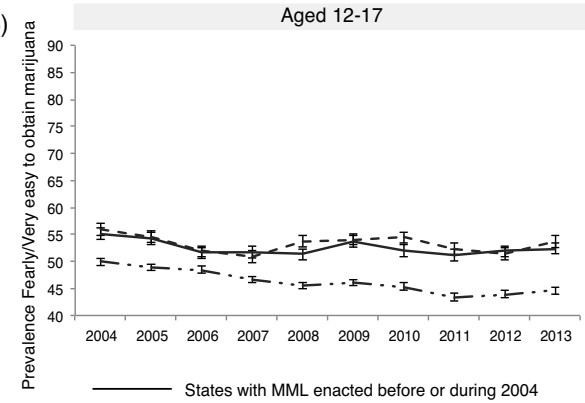

Aged 18-25
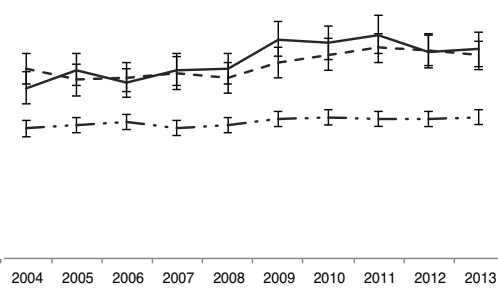
Year

- - - States with MML enacted between 2005-2013

Aged 18-25

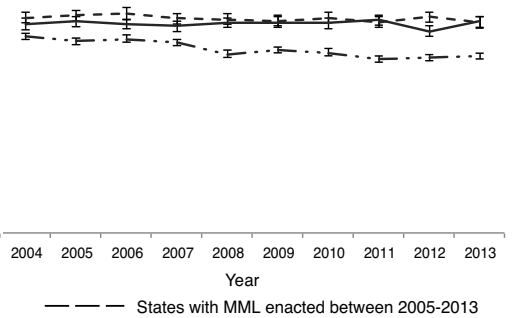

Aged 26 or oler

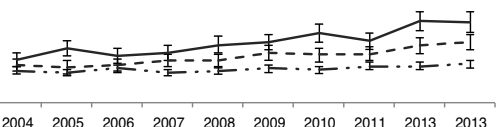

-...-. - States without MML by 2013

Aged 26 or oler

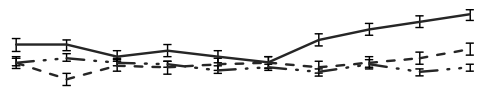

$\begin{array}{llllllllll}2004 & 2005 & 2006 & 2007 & 2008 & 2009 & 2010 & 2011 & 2012 & 2013\end{array}$

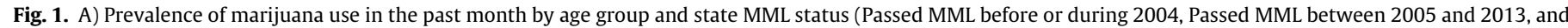
States without MML by 2013). ${ }^{\mathrm{a}} \mathrm{B}$ ) Prevalence of availability of marijuana (fairly or very easy to obtain marijuana) by age group and state MML status.

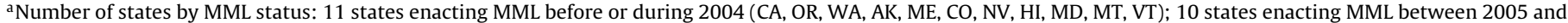
2013 (RI, NM, MI, AZ, NJ, DE, CT, MA, IL, NH); and 29 states without MML by 2013.

Abbreviations: MML: Medical marijuana laws.

Table 1

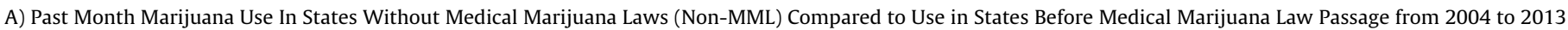
(Model 1). B) Past Month Marijuana Use Before versus After Medical Marijuana Law (MML) Passage from 2004 to 2013 (Model 1 )

\begin{tabular}{|c|c|c|c|c|c|}
\hline & Non-MML Prevalence ${ }^{a}$ & Before MML Prevalence $^{b}$ & Adjusted Odds Ratio (Before vs. Non-MML) & $95 \% \mathrm{CI}$ & p-value \\
\hline Age $12-17$ & 5.48 & 8.55 & 1.61 & $1.41,1.84$ & $<0.001$ \\
\hline Age $18-25$ & 11.60 & 19.01 & 1.79 & $1.57,2.03$ & $<0.001$ \\
\hline Age $26+$ & 3.87 & 5.87 & 1.55 & $1.36,1.77$ & $<0.001$ \\
\hline
\end{tabular}

B)

\begin{tabular}{llllll}
\hline & Before MML Prevalence $^{\mathrm{b}}$ & After MML Prevalence $^{\mathrm{c}}$ & Adjusted Odds Ratio (After vs. Before) & $95 \% \mathrm{CI}$ & $\mathrm{p}$-value \\
\hline Age 12-17 & 8.55 & 8.77 & 1.03 & $0.97,1.09$ \\
Age 18-25 & 19.01 & 18.59 & 0.97 & 0.34 \\
Age 26+ & 5.87 & 7.15 & 1.24 & 0.27 \\
\hline
\end{tabular}

All models were adjusted by: Individual-level covariates: sex, race/ethnicity, population density; State-level covariates: proportion of each state's population male, white, aged 10-24, and at least high school education in population aged $>25$ years, state unemployment rate and median household income.

a Adjusted Prevalence from Model 1 in non-MML states (27 non-MML states by 2013).

b Adjusted Prevalence from Model 1 in MML states before the enactment of MML (10 states have before MML data available).

c Adjusted Prevalence from Model 1 in MML states after the enactment of MML (21 states have after MML data available, 11 that passed MML prior to or during 2004 and 10 that passed MML between 2005 and 2013).

on a change in perception of availability of marijuana among adolescents (12-17) or young adults (18-25) (Table 2B), but there was a significant increase in perceiving marijuana as easily available, from $59.4 \%$ to $61.8 \%$, among those $26+(\mathrm{AOR}=1.11,95 \% \mathrm{CI}: 1.07$, 1.15). This significant increase in perceiving marijuana as easily available was found in all three subgroups of those aged $26+$ (see Supplementary Table S3).

Across age groups individuals that perceived marijuana as easily available (vs. difficult) had a much higher likelihood of past-month marijuana use (Table 3 ). This was consistent across all age groups, including those 26-39, 40-64, 65+ (Supplementary Table S4). Of note, among those 26 and older, the magnitude of the association between MML and the prevalence of marijuana use decreased by $19 \%$ when perceived availability was added to model. The magnitude of the association between MML and marijuana use also decreased by $14.7 \%, 14.5 \%$, and $13.0 \%$, in those $26-39,40-64,65+$, respectively after including perceived availability in the model.

\section{Discussion}

This study shows an increase in the prevalence of past-month marijuana use from the before to the after MML period in adults 26-39, 40-64, and 65+ between 2004 and 2013. There was no increase in the prevalence of past-month in adolescent or young adult comparing the before and after MML periods in states that implemented MML. These findings are consistent with findings from prior studies (Anderson et al., 2015b; Choo et al., 2014; Harper et al., 2012; Hasin et al., 2015; Lynne-Landsman et al., 2013; Wall et al., 2011). Moreover, there was also no increase in perceived availability of marijuana among adolescents or young adults, which 
Table 2

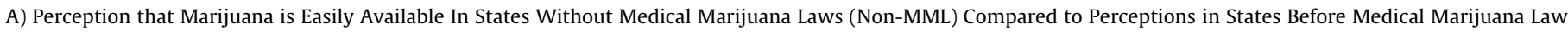

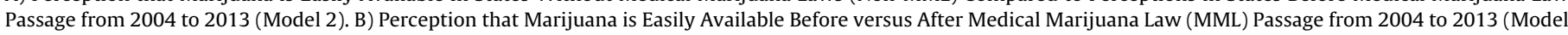
2).

\begin{tabular}{|c|c|c|c|c|c|}
\hline \multicolumn{6}{|l|}{ A) } \\
\hline & Non-MML Prevalence ${ }^{a}$ & Before MML Prevalence ${ }^{b}$ & Adjusted Odds Ratio & $95 \% \mathrm{CI}$ & p-value \\
\hline Age $12-17$ & 44.5 & 52.1 & 1.35 & $1.25,1.47$ & $<0.001$ \\
\hline Age $18-25$ & 72.8 & 79.2 & 1.43 & $1.32,1.55$ & $<0.001$ \\
\hline Age $26+$ & 55.0 & 59.4 & 1.20 & $1.10,1.30$ & $<0.001$ \\
\hline \multicolumn{6}{|l|}{ B) } \\
\hline & Before MML Prevalence ${ }^{b}$ & After MML Prevalence ${ }^{c}$ & Adjusted Odds Ratio & $95 \% \mathrm{CI}$ & p-value \\
\hline Age $12-17$ & 52.1 & 52.7 & 1.02 & $0.99,1.06$ & 0.19 \\
\hline Age $18-25$ & 79.2 & 79.3 & 1.00 & $0.97,1.04$ & 0.88 \\
\hline Age $26+$ & 59.4 & 61.8 & 1.11 & $1.07,1.15$ & $<0.001$ \\
\hline
\end{tabular}

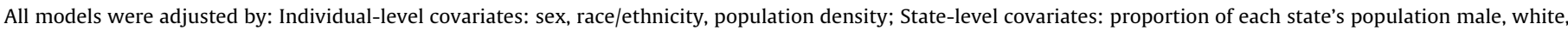
aged $10-24$, and at least high school education in population aged $>25$ years, state unemployment rate and median household income.

a Adjusted Prevalence from Model 2 in non-MML states (27 non-MML states by 2013).

b Adjusted Prevalence from Model 2 in MML states before the enactment of MML (10 states have before MML data available).

c Adjusted Prevalence from Model 2 in MML states after the enactment of MML (21 states have after MML data available, 11 that passed MML prior to or during 2004 and 10 that passed MML between 2005 and 2013).

Table 3

Past Month Marijuana Use in Relation to Perceived Availability from 2004 to 2013 (Model 3).

\begin{tabular}{|c|c|c|c|c|c|}
\hline & Adjusted Odds Ratio & $95 \% \mathrm{CI}$ & p-value & $\begin{array}{l}\text { Prevalence of Use with } \\
\text { easy availability }\end{array}$ & $\begin{array}{l}\text { Prevalence of Use with } \\
\text { difficult availability }^{\mathrm{a}}\end{array}$ \\
\hline \multicolumn{6}{|c|}{ Perceived Availability (Easy vs. Difficult) } \\
\hline Age $12-17$ & 15.57 & $14.66,16.54$ & $<0.001$ & 15.1 & 1.1 \\
\hline Age $18-25$ & 5.63 & $5.40,5.88$ & $<0.001$ & 20.3 & 4.3 \\
\hline Age $26+$ & 5.73 & $5.42,6.07$ & $<0.001$ & 9.1 & 1.7 \\
\hline
\end{tabular}

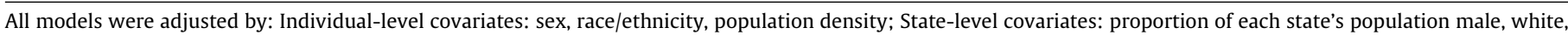
aged 10-24, and at least high school education in population aged $>25$ years, state unemployment rate and median household income.

a Adjusted Prevalence of past-month marijuana use from Model 3 among individuals perceiving marijuana availability as easy or difficult controlling for MML.

suggest that, consistent with other studies (Wall et al., 2011; Hasin et al., 2015), externalities of MML among adolescents and young adults may have not occurred to date. Finally, perceived availability was associated with both MML and marijuana use in adults 26-39, 40-64 and 65+, revealing a potential mechanism that may explain the increase in use among adults. However, the fact that the prevalence of past-month adult marijuana was already higher before MML passage when compared to states that have not yet passed MML, suggest that this could be a more complex relationship, with other factors besides perceived availability potentially being associated with marijuana use patterns in the population.

While we only assessed cross-sectional relationships across time, it is possible that the association between perceived availability and marijuana use is bi-directional (i.e., not only having a perception of marijuana being available would lead to marijuana use, but already marijuana users could be more likely to endorse that marijuana is easily available). There are different scenarios that could explain the increase in perceived availability of marijuana among those 26+ living in MML states during the post-legislation period: 1) MML it is in fact associated with increases in the availability of marijuana both for medical and non-medical purposes as argued by Smart (2015); 2) those 26 and older who started using marijuana after MML were enacted could have a different perception of the availability of marijuana because they are now actively accessing the medical marijuana market as marijuana users, even when the overall availability of marijuana remained relatively stable; 3 ) media reports about MML enactment could influence individuals' perception of marijuana availability, even when such availability has not increased; 4) other factors, different from MML, such as the decriminalization of marijuana possession (Pacula and Sevigny, 2014), which occurred simultaneously or together with the enactment of MML, could be associated with greater availability of marijuana and in turn with individuals' perception of marijuana availability.

The observed increase in the prevalence of past-month marijuana use among adults 26-39, 40-64, and 65+ could be in part due to increased availability of medical marijuana to treat medical conditions in individuals registered in medical marijuana programs, mostly adults 30 and older (Fairman, 2016). However, this increase could be also due to the increases in the diversion of medical marijuana to individuals using it for recreational purposes (Nussbaum et al., 2015; RMHIDTA, 2014; Wirfs-Brock et al., 2010). The exact nature of the role of marijuana availability on marijuana use patterns (e.g., relaxing norms and changing attitudes towards marijuana use) is not clear, but our findings suggest that availability could be a factor contributing to increases in marijuana use among adults after MML are enacted in a similar way as it has been suggested for other substances such as alcohol (Campbell et al., 2009).

Limitations are noted. Current perceived availability was only measured in the NSDUH by a single question and we are not aware of studies evaluating the reliability of this item in sub-groups of adolescents and young adults; SAMHSA staff (personal communication) believes there is no reason that adolescents should interpret this question differently from adults. It is possible however, that if this question provides an unreliable measure of the construct among adolescents, MML enactment would not have an effect on this variable among adolescents. It should be noted that the question used in NSDUH is very similar to the perceived availability of marijuana question used in the Monitoring the Future survey, a measure believed to have a rather high level of face validity (Miech et al., 2015). In addition, given that we used cross-sectional data we are unable to identify if perceived availability preceded marijuana use or not, thus we could not identify the temporality of the asso- 
ciation. Additionally, NSDUH only has data for years 2004-2013, and therefore we were unable to examine the effects of MML in states enacting these laws before 2004, and it is possible that different effects could have occurred in these states. Nonetheless, a major strength of the present study is its use of a large nationally representative sample, allowing for generalization of findings to the U.S. non-institutionalized population. Finally, there is evidence (Pacula et al., 2015; Wen et al., 2015) showing that MML are in fact heterogeneous, and that some aspects, such as allowances on home cultivation or dispensaries, might have a role in changes in several health outcome indicators. Future research should examine what elements of MML and also other local aspects contribute to changes in marijuana use outcomes and perceptions of availability of marijuana in the general population.

In conclusion, this study shows that, from 2004 to 2013, in the U.S. general population of the 23 states with MML by 2015, there was evidence for an increase in the prevalence of past-month marijuana use from the before to the after MML period in adults 26 and older. Perceived availability was associated with both MML and marijuana use among adults 26 and older. Other unexplored factors need to be examined to better understand why the prevalence of past-month marijuana use increased in adults 26 and older following MML but remained stable among younger cohorts.

\section{Role of funding}

This study was partially funded by the National Institutes of Health, National Institute on Drug Abuse (NIH-NIDA) [grants R01 DA037866 (PI: Martins), R01 DA034244 (PI: Hasin), K01DA030449 (PI: Cerdá), and T32 DA031099 (PI: Hasin)]; National Institutes of Health, National Institute of Alcohol and Alcoholism (NIH-NIAAA) [grant K01AA021511 (PI: Keyes)]. Dr. Santaella is funded by the J. William Fulbright and the Colciencias doctoral scholarships. Dr. Hasin is also funded by the New York State Psychiatric Institute.

\section{Contributors}

Dr. Martins, Dr. Mauro and Mr. Santaella design and conceptualized the study. Dr. Mauro and Mr. Santaella analyzed the data under Dr. Martins' and Wall' supervision and also drafted sections of the manuscript. Dr. Martins wrote the first full draft of the manuscript. All other authors critically reviewed and edited the manuscript and approved the final version for submission.

\section{Conflict of interest}

The authors have no conflict of interest to declare.

\section{Acknowledgments}

The authors would like to thank the National Survey on Drug Use and Health NSDUH study respondents and Substance Abuse and Mental Health Service Administration (SAMHSA) for access to the restricted-use NSDUH files.

\section{Appendix A. Supplementary data}

Supplementary data associated with this article can be found, in the online version, at http://dx.doi.org/10.1016/j.drugalcdep.2016. 10.004 .

\section{References}

Anderson, D., Hansen, B., Rees, D., 2015a. Medical marijuana laws and teen marijuana use. Am. Law Econ. Rev. 17, 4-34.
Anderson, K.G., Sitney, M., White, H.R., 2015b. Marijuana motivations across adolescence: impacts on use and consequences. Subst. Use Misuse 50, 292-301.

Bestrashniy, J., Winters, K.C., 2015. Variability in medical marijuana laws in the United States. Psychol. Addict. Behav. 29, 639-642.

Bonn-Miller, M.O., Boden, M.T., Bucossi, M.M., Babson, K.A., 2014. Self-reported cannabis use characteristics, patterns and helpfulness among medical cannabis users. Am. J. Drug Alcohol Abuse 40, 23-30.

CBHSQ 2015. National Survey on Drug Use and Health Series [data Files and Codebook]. U.S. Dept. of Health and Human Services (HHS), Substance Abuse and Mental Health Services Administration (SAMHSA), Center for Behavioral Health Statistics and Quality (CBHSQ), Rockville, MD, Available at: http:// www.icpsr.umich.edu/icpsrweb/SAMHDA (accessed 31.07.15.).

Campbell, C.A., Hahn, R.A., Elder, R., Brewer, R., Chattopadhyay, S., Fielding, J., Naimi, T.S., Toomey, T., Lawrence, B., Middleton, J.C., Task Force on Community Preventive Services, 2009. The effectiveness of limiting alcohol outlet density as a means of reducing excessive alcohol consumption and alcohol-related harms. Am. J. Prev. Med. 37, 556-569.

Cerdá, M., Wall, M., Keyes, K.M., Galea, S., Hasin, D., 2012. Medical marijuana laws in 50 states: investigating the relationship between state legalization of medical marijuana and marijuana use, abuse and dependence. Drug Alcohol Depend. 120, 22-27.

Choo, E.K., Benz, M., Zaller, N., Warren, O., Rising, K.L., McConnell, K.J., 2014. The impact of state medical marijuana legislation on adolescent marijuana use. J. Adolesc. Health 55, 160-166.

de Boor, C., 1978. A Practical Guide to Splines. Springer-Verlag, New York.

Ennett, S.T., Flewelling, R.L., Lindrooth, R.C., Norton, E.C., 1997. School and neighborhood characteristics associated with school rates of alcohol, cigarette, and marijuana use. J. Health Soc. Behav. 38, 55-71.

Fairman, B.J., 2016. Trends in registered medical marijuana participation across 13 US states and District of Columbia. Drug Alcohol Depend. 159, 72-79.

Friese, B., Grube, J.W., 2013. Legalization of medical marijuana and marijuana use among youths. Drugs 20, 33-39.

Hanson, T., Austin, G., Lee-Bayha, J., 2003. Student Health Risks, Resilience and Academic Performance in California. Health and Human Development Program, WestEd., Safe and Healthy Kids Program Office, Sacramento, California.

Harper, S., Strumpf, E., Kaufman, J., 2012. Do medical marijuana laws increase marijuana use? Replication study and extension. Ann. Epidemiol. 22, 207-212.

Harrison, L., Martin, S., Enev, T., Harrington, D., 2007. Comparing Drug Testing And Self-Report Of Drug Use Among Youths And Young Adults In The General Population (DHHS Publication No. SMA 07-4249, Methodology Series M-7). Substance Abuse and Mental Health Services Administration, Office of Applied Studies, Rockville, MD.

Hasin, D.S., Wall, M., Keyes, K.M., Cerdá, M., Schulenberg, J., O’Malley, P.M., Galea, S., Pacula, R., Feng, T., 2015. Medical marijuana laws and adolescent marijuana use in the USA from 1991 to 2014: results from annual, repeated cross-sectional surveys. Lancet Psychiatry 2, 601-608.

Hunter, S., Feder, M., Granger, B., Piper, L., Chromy, J., 2005. Reliability Study Pretest Analysis, in Section 18, National Survey on Drug Use and Health: Methodological Resource Book. Prepared for the Substance Abuse and Mental Health Services Administration, Office of Applied Studies, Under Contract No. 283-2004-00022, RTI/0209009. RTI International, Research Triangle Park, NC.

Khatapoush, S., Hallfors, D., 2004. Sending the wrong message: did medical marijuana legalization in California change attitudes about and use of marijuana? J. Drug Issues 34, 751-770.

Kokkevi, A., Terzidou, M., Politikou, K., Stefanis, C., 2000. Substance use among high school students in Greece: outburst of illicit drug use in a society under change. Drug Alcohol Depend. 58, 181-188.

Little, R., 2004. To model or not to model? Competing modes of inference for finite population sampling. J. Am. Stat. Assoc. 99, 546-556.

Lynne-Landsman, S.D., Livingston, M.D., Wagenaar, A.C., 2013. Effects of state medical marijuana laws on adolescent marijuana use. Am. J. Public Health 103, 1500-1506.

Miech, R.A., Johnston, L.D., O’Malley, P.M., Bachman, J.G., Schulenberg, J.E., 2015. Monitoring The Future National Survey Results On Drug Use, 1975-2014, vol. I. Secondary School Students, Institute for Social Research, The University of Michigan, Ann Arbor, Available at http://monitoringthefuture.org/pubs. html\#monographs (accessed August 2016).

NDIC, 2010. Drug Availability in the United States. U.S. Department of Justice, National Drug Intelligence Center, Available at: https://www.justice.gov/ archive/ndic/pubs38/38661/marijuana.htm (accessed 28.04.16.).

Nussbaum, A.M., Thurstone, C., McGarry, L., Walker, B., Sabel, A.L., 2015. Use and diversion of medical marijuana among adults admitted to inpatient psychiatry. Am. J. Drug Alcohol Abuse 41, 166-172.

Pacula, R.L., Sevigny, E.L., 2014. Marijuana liberalization policies: why we can't learn much from policy still in motion. J. Policy Anal. Manag. 33, 212-221.

Pacula, R., Hunt, P., Boustead, A., 2014. Words can be deceiving: a review of variation among legally effective medical marijuana laws in the United States. J. Drug Policy Anal. 7, 1-19.

Pacula, R.L., Powell, D., Heaton, P., Sevigny, E.L., 2015. Assessing the effects of medical marijuana laws on marijuana use: the devil is in the details. J. Policy Anal. Manag. 34, 7-31

Palamar, J.J., Ompad, D.C., Petkova, E., 2014. Correlates of intentions to use cannabis among US high school seniors in the case of cannabis legalization. Int J. Drug Policy 25, 424-435. 
Piontek, D., Kraus, L., Bjarnason, T., Demetrovics, Z., Ramstedt, M., 2013. Individual and country-level effects of cannabis-related perceptions on cannabis use. A multilevel study among adolescents in 32 European countries. J. Adolesc. Health 52, 473-479.

Piper, L., Meyer, M., Snodgrass, J., 2006. Reliability Study Pretest Final Report. Substance Abuse and Mental Health Services Administration, Office of Applied Studies, Rockville, MD (Contract No. 283-2004-00022, RTI/0209009).

RMHIDTA, 2014. Legalization of marijuana in Colorado, the impact. vol. 2. Rocky Mountain High Intensty Drug Trafficking Area. Available at: http://www.in. gov/ipac/files/August_2014_Legalization_of_MJ_in_Colorado_the_Impact(1).pdf (accessed March 2016).

SAMHSA, 2006. Results From the National Survey on Drug Use and Health: National Findings. NSDUH Series H-30, DHHS Publication No. SMA 06-4194. Substance Abuse and Mental Health Services Administration, Office of Applied Studies, Rockville, MD.

SAMHSA, 2007. Results From the 2006 National Survey on Drug Use and Health: National Findings. NSDUH Series H-32, DHHS Publication No. SMA 07-4293. Substance Abuse and Mental Health Services Administration, Office of Applied Studies, Rockville, MD.

SAMHSA, 2010. Reliability of Key Measures in the National Survey on Drug Use and Health (Office of Applied Studies, Methodology Series M-8, HHS Publication No. SMA 09-4425). Substance Abuse and Mental Health Services Administration, Rockville, MD.

SAMHSA, 2012. Results from the 2011 National Survey on Drug Use and Health: Summary of National Findings, NSDUH Series H-44, HHS Publication No. (SMA) 12-4713. Substance Abuse and Mental Health Services Administration, Rockville, MD.

Salomonsen-Sautel, S., Sakai, J.T., Thurstone, C., Corley, R., Hopfer, C., 2012. Medical marijuana use among adolescents in substance abuse treatment. J. Am. Acad. Child Adolesc. Psychiatry 51, 694-702.

Schuermeyer, J., Salomonsen-Sautel, S., Price, R.K., Balan, S., Thurstone, C., Min, S.J., Sakai, J.T., 2014. Temporal trends in marijuana attitudes, availability and use in Colorado compared to non-medical marijuana states: 2003-11. Drug Alcohol Depend. 140, 145-155.

Shi, Y., 2016. The availability of medical marijuana dispensary and adolescent marijuana use. Prev. Med. 91, 1-7.
Smart, R., 2015. The Kids Aren't Alright but Older Adults Are Just Fine: Effects of Medical Marijuana Market Growth on Substance Use and Abuse. Social Science Research Network, Available from: http://ssrn.com/abstract=2574915 or http://dx.doi.org/10.2139/ssrn.2574915.

Steppan, M., Kraus, L., Piontek, D., Siciliano, V., 2013. Are cannabis prevalence estimates comparable across countries and regions? A cross-cultural validation using search engine query data. Int. J. Drug Policy 24, 23-29.

ter Bogt, T., Schmid, H., Gabhainn, S.N., Fotiou, A., Vollebergh, W., 2006. Economic and cultural correlates of cannabis use among mid-adolescents in 31 countries. Addiction 101, 241-251.

ter Bogt, T.F., de Looze, M., Molcho, M., Godeau, E., Hublet, A., Kokkevi, A., Kuntsche, E., Nic Gabhainn, S., Franelic, I.P., Simons-Morton, B., Sznitman, S., Vieno, A., Vollebergh, W., Pickett, W., 2014. Do societal wealth, family affluence and gender account for trends in adolescent cannabis use? A 30 country cross-national study. Addiction 109, 273-283.

Thurstone, C., Lieberman, S.A., Schmiege, S.J., 2011. Medical marijuana diversion and associated problems in adolescent substance treatment. Drug Alcohol Depend. 118, 489-492.

UNODC, 2015. World Drug Report. United Nations publication, Sales No. E.15. XI.6, Available at: https://www.unodc.org/documents/wdr2015/World_Drug_ Report_2015.pdf (accessed 28.04.16.)

Wall, M.M., Poh, E., Cerdá, M., Keyes, K.M., Galea, S., Hasin, D.S., 2011. Adolescent marijuana use from 2002 to 2008: higher in states with medical marijuana laws, cause still unclear. Ann. Epidemiol. 21, 714-716.

Wen, H., Hockenberry, J.M., Cummings, J.R., 2015. The effect of medical marijuana laws on adolescent and adult use of marijuana, alcohol, and other substances. J. Health Econ. 42, 64-80.

Williams, A., 2016. Medical and recreational marijuana policy: from prohibition to the rise of regulation. In: Compton, M. (Ed.), Marijuana and Mental Health. American Psychiatric Publishing Inc., New York.

Wirfs-Brock, J., Seaton, L., Sutherland, A., 2010. Colorado Medical Marijuana Surplus Leaks To Black Market. Daily Camera News, Available at: http://www. dailycamera.com/news/ci_15644376 (accessed March 2016). 